\title{
Gender differences and caffeine impact in adenosine-
}

\section{induced hyperemia}

Martin Lyngby Lassen, $\mathrm{PhD}^{1}$, Christina Byrne, MD, $\mathrm{PhD}^{1}$, Majid Sheykhzade, $\mathrm{PhD}^{2}$, Mads Wissenberg MD, $\mathrm{PhD}^{3}$, Preetee Kapisha Hurry, MD¹, Anne Vibeke Schmedes, M Pharm, $\mathrm{PhD}^{4}$, Andreas Kjaer, MD, PhD, DMSc ${ }^{1}$, Philip Hasbak, MD, DMSc ${ }^{1}$

${ }^{1}$ Department of Clinical Physiology, Nuclear Medicine and PET and Cluster for Molecular Imaging, Rigshospitalet and University of Copenhagen

${ }^{2}$ Department of Drug Design and Pharmacology, Faculty of Health and Medical Sciences, University of Copenhagen, Copenhagen, Denmark

${ }^{3}$ Department of Cardiology, Copenhagen University Hospital, Gentofte, Denmark.

${ }^{4}$ Department of Biochemistry and Immunology, Lillebaelt Hospital, Vejle, Denmark

The first author is a postdoctoral fellow in training.

Corresponding Author:

Martin Lyngby Lassen, PhD, Department of Clinical Physiology, Nuclear Medicine and PET and Cluster for Molecular Imaging, section 4011, Rigshospitalet and University of Copenhagen, Blegdamsvej 9, 2100 Copenhagen, Denmark

Tel: +45 35453520 Fax: +45 35454015

Email: martin.lyngby.lassen@regionh.dk

Short title: Caffeine and adenosine stress MBF

Immediate Open Access: Creative Commons Attribution 4.0 International License (CC BY) allows users to share and adapt with attribution, excluding materials credited to previous publications.

License: https://creativecommons.org/licenses/by/4.0/. Details: https://jnm.snmjournals.org/page/permissions.

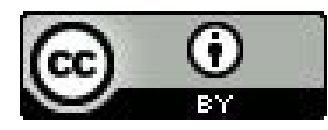




\section{ABSTRACT}

\section{Background}

Caffeine consumption before adenosine stress myocardial perfusion imaging (MPI) is known to affect the hemodynamic response and, thus, reduce the stress myocardial blood flow (MBF) and myocardial flow reserve (MFR) assessments. However, it is not clear if any gender-specific differences in the hemodynamic response following caffeine consumption exist. This study aimed to evaluate if such differences exist and, if so, their impact on MBF and MFR assessments.

\section{Methods}

This study comprised 40 healthy volunteers (19 women). All volunteers underwent four serial rest/stress MPI sessions employing Rubidium-82; two sessions were acquired without controlled caffeine consumption, and two sessions following oral ingestion of either $100 \mathrm{mg}$ and $300 \mathrm{mg}$ caffeine or $200 \mathrm{mg}$ and $400 \mathrm{mg}$ caffeine. For the caffeine imaging sessions, caffeine was ingested orally $1 \mathrm{hr}$ before the MPI scan.

\section{Results}

Increase in plasma caffeine concentration (PCC) (mg/l) following consumption of caffeine was larger in women (MPI session without caffeine vs. MPI session with caffeine: women $=0.3 \pm 0.2$ vs. $5.4 \pm 5.1$, men $=0.1 \pm 0.2$ vs. $2.7 \pm 2.6$, both $p<0.001)$. Caffeine consumption led to reduced stress MBF and MFR assessments for men while no changes were reported for women (women $(\mathrm{PCC}<1 \mathrm{mg} / \mathrm{l}$ vs $\mathrm{PCC} \geq 1 \mathrm{mg} / \mathrm{l}$ ): stress $\mathrm{MBF}=3.3 \pm 0.6$ vs. $3.0 \pm 0.8 \mathrm{ml} / \mathrm{g} / \mathrm{min}, \mathrm{p}=0.07 ; \mathrm{MFR}=3.7 \pm 0.6$ vs. $3.5 \pm 1.0, \mathrm{p}=0.35 ;$ Men $(P C C<1 \mathrm{mg} / \mathrm{l}$ vs $P C C \geq 1 \mathrm{mg} / \mathrm{l}):$ stress $\mathrm{MBF}=2.7 \pm 0.7$ vs. $2.1 \pm 1.0 \mathrm{ml} / \mathrm{g} / \mathrm{min}, \mathrm{p}=0.005, \mathrm{MFR}=3.8 \pm 1.0$ vs. 
3.1 $\pm 1.4, p=0.018)$. Significant differences in the stress MBF were observed for the two genders (both $p \leq 0.001$ ), while similar MFR were reported (both $p \geq 0.12$ ).

\title{
Conclusion
}

Associations between increases in PCC and reductions in stress MBF and MFR were observed for men, while women did not have the same hemodynamic response. Stress MBF was affected at lower plasma caffeine concentrations in men than women.

Keywords: Caffeine; adenosine; myocardial flow reserve; positron emission tomography; stress myocardial blood flow

\author{
Abbreviations \\ CVR Coronary vascular resistance \\ IQR Interquartile range \\ MBF $\quad$ Myocardial blood flow \\ MFR Myocardial flow reserve \\ MPI Myocardial perfusion imaging \\ PET/CT positron emission tomography/computed tomography \\ RPP Rate pressure product \\ ${ }^{82} \mathbf{R b} \quad$ Rubidium-82
}




\section{INTRODUCTION}

Myocardial blood flow (MBF) and myocardial flow reserve (MFR) assessments have become central in the clinical assessment of cardiac Rubidium-82 ( $\left.{ }^{82} \mathrm{Rb}\right)$ in Positron Emission Tomography (PET). The valid measures of stress MBF and MFR require a full hemodynamic response during the acquisition. Adenosine is a frequently used pharmacological stressor that attaches to the $A_{2 A}$-adenosine receptor that mediates coronary vasodilation (1,2). When using adenosine as a pharmacological stressor, patients are recommended to refrain from beverages, food, and analgesics containing caffeine for at least 12 hours prior to the imaging session to avoid subpar stressing of the patients as caffeine non-selectively blocks the $\mathrm{A}_{2 \mathrm{~A}}$-adenosine receptor (1-3). Consumption of caffeine has been shown to reduce the hemodynamic response even at plasma concentrations as low as $1 \mathrm{mg} / \mathrm{l}$, which might introduce false-positive findings following the consequential reductions in the stress MBF and MFR (4-6). While elevated caffeine plasma concentrations are known to affect the hemodynamic response when using adenosine as a stressing agent $(4,5,7)$, it is unknown whether any gender-specific differences in the hemodynamic response exist $(5,8)$.

This study aimed to evaluate the potential influence of gender on the association between plasma caffeine concentrations and stress MBF and MFR, respectively. 


\section{MATERIALS AND METHODS}

\section{Study Population}

This study comprised 40 young, healthy volunteers (19 women) (median age $=23$ years, interquartile range $(\mathrm{IQR})=[22 ; 25])$ recruited for rest/adenosine-stress myocardial perfusion ${ }^{82} \mathrm{Rb}-\mathrm{PET} / \mathrm{Computed} \mathrm{Tomography} \mathrm{(CT)} \mathrm{from} \mathrm{September} 2016$ to March 2017. Median volunteer weight was $70.0 \mathrm{~kg}[\mathrm{IQR}=62 ; 79.5 \mathrm{~kg}]$, with corresponding median BMI on 22 [IQR $=20.5 ; 23.8]$. The volunteers underwent four serial PET/CT imaging sessions within 27 days [IQR $=17 ; 36]$, acquired with and without controlled caffeine consumption before the imaging session. Inclusion criteria were age $>18$ years, no participation in studies testing drugs, no regular consumption of medicine, no known medical condition, and no use of tobacco and euphoric substances (except alcohol) within three months prior to study participation. Exclusion criteria were pregnancy, allergy, intolerance to theophylline or adenosine, any prior medical history of asthma, or inability to adhere to the study protocol. The Scientific Ethics Committee of the Capital Region of Denmark [protocol number $\mathrm{H}-15009293$ ] and the Danish Data Protection Agency approved this study, and all volunteers provided informed oral and written consent.

\section{Imaging Protocol}

PET Acquisition. The forty healthy volunteers were divided into two groups, both undergoing four ${ }^{82} \mathrm{Rb}-\mathrm{PET} / \mathrm{CT}$ imaging sessions, each consisting of an ${ }^{82} \mathrm{Rb}$ rest/stress protocol (Fig. 1A). All PET acquisitions, targeting injection doses of $1100 \mathrm{MBq}(30 \mathrm{mCi})$ ${ }^{82} \mathrm{Rb}$, were obtained in 3D mode on a 128 slice Siemens Biograph mCT PET/CT system and stored in listmode format (9). Pharmacological stressing was obtained using 
adenosine infused at $140 \mathrm{mg} / \mathrm{kg} / \mathrm{min}$ for 6 minutes with PET emission acquisition starting 2.5 min into the infusion (Fig. 1A). Before the rest scans, the volunteers had a low-dose CT for attenuation correction purposes (120kVp; effective tube current, $26 \mathrm{~mA}$ [11mAs quality reference]) acquired using a free-breathing protocol (10). The volunteers were instructed to abstain from caffeine at least 24 hours before each of the four imaging sessions. All study volunteers underwent two imaging sessions without ingestion of caffeine and two imaging sessions following the ingestion of caffeine in a controlled setting using caffeine tablets (Fig. 1B). The caffeine tablets were dissolved in hot water and orally ingested 60 minutes prior to the rest perfusion scans. One-half of the volunteers had two serial imaging sessions with ingestion of $100 \mathrm{mg}$ and $300 \mathrm{mg}$ of caffeine, while the other half of the study volunteers underwent two serial imaging sessions following the ingestion of $200 \mathrm{mg}$ and $400 \mathrm{mg}$ of caffeine (Fig. 1B). The four imaging sessions were obtained in a randomized fashion. For this study, the plasma caffeine concentration is reported at the time of the stress MPI, thus, as an average of the measurements obtained at 75 and 90 minutes. All plasma caffeine concentrations were measured using highperformance liquid chromatography - mass spectrometry (LC-MS/MS).

PET reconstruction protocol and data processing. The 6 minutes long PET acquisitions were reconstructed into dynamic image-series consisting of 18 frames $(1 \times 10 s, 8 \times 5 s, 3 \times 10 s, 2 \times 20 s, 4 \times 60 s)$ using the vendor iterative Ordered-Subset Expectation-Maximization 3D reconstruction method (2 iterations, 21 subsets), with corrections for time-of-flight and point-spread function. All data were smoothened using 
6.5-mm Gaussian post-filtering. Myocardial blood flow was calculated using the Lortie model (11), and MFR was calculated as the ratio of the stress and rest MBF (12) in dedicated software (QPET, Cedars-Sinai Medical Center, Los Angeles, California, USA (13). We report MBF and MFR with and without corrections for the rate-pressure product $(\mathrm{RPP})$, defined as RPP $=($ systolic blood pressure $) /($ Heart rate $) ;$ corrected rest MBF $=($ rest MBF $/$ RPP $\times 6500$ and corrected stress MBF $=($ stress MBF)/RPP $\times 8600$. Stress MBF and MFR above 3.0 were considered normal (14).

Repeatability. Test-retest repeatability of the rest and stress MBF, and the MFR were calculated for the baseline scans (0mg caffeine ingested) with plasma caffeine concentrations $<1 \mathrm{mg} / \mathrm{L}$ using the coefficient of variance (15).

Coronary vascular resistance (CVR). CVR was obtained for all scans using equation $2(16)$.

$$
\text { CVR }=0.33 \times \frac{(2 \times \text { diastolic blood pressure }+ \text { systolic blood pressure })}{M B F}
$$

In (2) is MBF representing the scan-specific MBF. Both diastolic and systolic blood pressures were obtained during the PET emission acquisitions.

Regression plots for correlation between ingested caffeine and blood plasma concentration caffeine were calculated for all scans, using averaged plasma caffeine concentrations obtained at 75 and 90 minutes.

Concentration-response curves were obtained using a nonlinear curve-fit model, and the half-maximal relaxation (EC50) was determined:

$$
y=\text { bottom }+\frac{(\text { top-bottom })}{1+10^{((\log E C 50-x) * \text { lope })}}
$$




\section{Statistical Analysis}

Differences in the MBF and MFR were quantified using multivariable assessments (ANOVA) in R. For descriptive analyses of continuous values, we used mean \pm standard deviation, range or median, and interquartile range. Two-tailed $p$-values less than 0.05 were considered statistically significant. All data were checked for normality using Sharpio-Wilk test. Dependency of MFR and caffeine ingestion was determined using a two-way ANOVA, with p-values less than 0.05 being considered significant. Regressional analyses between plasma caffeine concentration and ingested caffeine were obtained for both genders. 


\section{RESULTS}

\section{Study Population}

A total of 40 volunteers underwent four serial PET/CT scans within 27 days, interquartile range $(\mathrm{IQR})=[17 ; 36]$. The volunteers had a median age of 23 years, IQR $=$ [22; 25] and 19 (47.5\%) were women. Average body mass index of the volunteers was $22.7 \pm 3.2($ women $=21.9 \pm 3.1$, men $=23.5 \pm 3.0, p=0.08)$. The median habitual daily coffee consumption was 2 cups, IQR $=[1.5 ; 3]$ (women $=2, I Q R=[1.5 ; 3]$, men $=2, I Q R=[1.5$; 3], $p=0.59$ ) per day representing a median caffeine intake from coffee of $200 \mathrm{mg} /$ day, IQR $=[150-300]$.

Of the 40 volunteers, one volunteer (man) was excluded due to failure to comply with the protocol. In addition, 4 scans were excluded because of significant motion during the scans (Omg scans: $\mathrm{N}=2 ; 200 \mathrm{mg}$ scan: $\mathrm{N}=1,400 \mathrm{mg}$ scan: $\mathrm{N}=1$ ). In total, 152 of the 160 acquired imaging sessions (95\%) were used for the subsequent analyses.

\section{Rest MBF}

Rest MBF assessments are shown in Fig. 2. Significant differences in the rest MBF assessments for the two genders were observed for MPI sessions with plasma caffeine concentrations $\leq 1 \mathrm{mg} / \mathrm{l}(\mathrm{p}<0.001)$ (no caffeine ingested) and $\geq 5 \mathrm{mg} / \mathrm{l}(\mathrm{p}=0.027)$ (caffeine ingested). Reduced heart rates were observed in the women following ingestion of caffeine while men had stable heart rates (Table 1). Similar test-retest repeatability coefficients were reported for the men and women $(16.1 \%$ and $13.5 \% \quad(p=0.42)$, respectively) (Table 2). Women had higher diastolic pressure than men $(62.3 \pm 6.4$ vs. $59.7 \pm 7.8 \mathrm{mmHg}, \mathrm{p}=0.02$ ) while lower systolic blood pressure was reported for women 
(104.6 \pm 12.1 vs. $112.3 \pm 12.4 \mathrm{mmHg}(p<0.001)$ (Tables 3 and 4). No difference in RPP was observed between the two genders (RPP rest: $6,394 \pm 1,400$ vs. $6,481 \pm 1,488(p=0.72)$ ) (Table 5). At rest, men had increased CVR when compared with women (Table 6).

\section{Stress MBF}

Women had higher heart rate and diastolic blood pressure, while systolic blood pressure was decreased when compared with men (heart rate: $85.1 \pm 16.8$ vs. $76.2 \pm 18.0$ beats per minute, diastolic blood pressure: $63.9 \pm 9.1$ vs. $57.3 \pm 8.8 \mathrm{mmHg}$, systolic blood pressure: $103.6 \pm 12.1$ vs. $109.4 \pm 12.3 \mathrm{mmHg}$, all $\mathrm{p}<0.005$ ) (Tables $1,3-4)$. No difference was observed for RPP in women and men $(8,833 \pm 2,098$ vs. $8,318 \pm 2,155, p=0.14$, Table $5)$.

Increased stress MBF assessments were reported for women when compared with men (stress MBF ( $\mathrm{ml} / \mathrm{g} / \mathrm{min}$ ): women vs. men (plasma caffeine concentration <1mg/l, no caffeine ingestion): $3.3 \pm 0.6$ vs. $2.7 \pm 0.7$, (plasma caffeine concentration $\geq 1 \mathrm{mg} / \mathrm{l}$, caffeine ingestion): $3.0 \pm 0.8$ vs. $2.1 \pm 1.0$, both $p<0.001$ ) (Fig. 3). Similar test-retest repeatability coefficients were reported for the men and women $(18.4 \%$ and $10.9 \% \quad(p=0.29)$, respectively) (Table 2). Significant changes in the hemodynamic response were observed for the men. In contrast, consistent stress MBF assessments were observed for women at plasma caffeine concentrations below $5 \mathrm{mg} / \mathrm{l}$ (Fig. 3). Corresponding to the change in the hemodynamic response, CVR was observed to increase for men even at low plasma caffeine concentrations, while no changes in CVR were observed for women (Table 6). Linear correlations between ingested caffeine and plasma concentrations of caffeine in both men and women were observed (Fig. 4). Increased plasma caffeine concentrations were measured in women compared with men for the same doses of ingested caffeine. 
Furthermore, almost a 3-fold increase in the sensitivity to caffeine was observed in men, with consequential reductions in the stress MBF assessments $(\mathrm{EC} 50(\mathrm{mg} / \mathrm{l})$ : Men $\approx 3$, Women $\approx 8$ ) (Fig. 5). Multivariable analyses including stress MBF, gender, and plasma caffeine concentrations revealed that both caffeine plasma concentration $(p<0.001)$, gender $(p<0.001)$, and the interaction of the two $(p=0.049)$ had a significant impact on stress MBF assessments.

\section{MFR}

Comparable MFR assessments were observed for women and men (Fig. 6), with similar repeatability coefficients for the two genders $($ Women $=12.9 \%$, Men $=20.6 \%$ $(p=0.21)$ ) (Table 2). However, MFR was reduced in men when plasma caffeine concentrations exceeded $5 \mathrm{mg} / \mathrm{l}$, while women had stable MFR at all plasma caffeine concentrations (Fig. 6). On an individual basis, MFR might be reduced even at plasma concentrations as low as $1.2 \mathrm{mg} / \mathrm{l}$ in men and $7.1 \mathrm{mg} / \mathrm{l}$ in women. Multivariable analyses including MFR, gender, and plasma caffeine concentrations revealed that gender and caffeine plasma concentration (both $p<0.001$ ), as well as the interaction of gender and plasma caffeine concentration $(p=0.049)$, had a significant impact on the MFR assessments. 


\section{DISCUSSION}

In this randomized controlled crossover trial, we evaluated the impact of plasma caffeine concentrations on stress MBF and MFR assessments in healthy volunteers. The main finding was a gender-specific response in stress MBF and MFR assessments when the volunteers had stress perfusion imaging following caffeine consumption. Multivariable analyses of the data revealed that gender, caffeine concentration, and the interaction of the two were strongly associated with changes in stress MBF and MFR. Hence, in healthy volunteers, caffeine intake was associated with a different hemodynamic response in men and women with consequential differences in the stress MBF and MFR assessments. Men were found more sensitive to caffeine concentration, where plasma caffeine concentrations as low as $1.2 \mathrm{mg} / \mathrm{L}$ might affect the perfusion estimates compared to $7.1 \mathrm{mg} / \mathrm{L}$ in women.

Baseline rest and stress MBF (plasma caffeine concentrations $<1 \mathrm{mg} / \mathrm{L}$ ) were increased in women, which might be explained by the estrogenic effect on the vascular tone (17). A number of studies have shown an evident trend for higher plasma caffeine and lower plasma paraxanthine (the most active caffeine metabolite) concentrations in women as compared with men, suggesting that women metabolize caffeine slower than men. Women with higher estrogen levels have been reported to have decreased cytochrome P450 1A2 enzyme activity and decreased caffeine clearance (18). Furthermore, a study has reported that women have $25 \%$ higher adenosine $\mathrm{A}_{1 \mathrm{~A}}$ (at mRNA level) receptor and $40 \%$ lower $A_{2 A}$ receptor expression (at mRNA level) than men and ovariectomized women (19). Thus, one can speculate that the differences in antagonistic potency of caffeine observed between men and women in our study is partially attributed 
to gender-related expression, adenosine receptor reserve and intracellular signaling. However, the mechanism(s) involved are likely to be more complex and need to be scrutinized in future studies.

Stress MBF and MFR were observed to fluctuate for the women at different plasma caffeine concentrations. These effects may be caused by the low number of measurements obtained for the plasma caffeine concentrations ranging between 1 and $5 \mathrm{mg} / \mathrm{L}$ and, thus, statistical noise. The general reduction in stress MBF for scans obtained following caffeine consumption reported for the male volunteers was in concurrence with previous studies $(5,7,16)$. Test-retest repeatability was tested for the baseline scans for all subjects with concurrent plasma caffeine concentrations $<1 \mathrm{mg} / \mathrm{L}$. In this context, testretest repeatability was found in concordance with previous studies evaluating the shortterm variation in rest MBF (15). The concurrent test-retest repeatability measures, therefore, suggest that reductions in the MBF and MFR assessments observed for high plasma caffeine concentrations were introduced by the ingestion of caffeine. This finding is supported by the observed physiological responses to caffeine ingestion. In concordance with previous studies, women had greater increases in diastolic blood pressure after caffeine administration than men (Table 3) $(20,21)$. One explanation for this effect may be men have a more sensitive baroreflex than women $(20,21)$. Further, gender differences in hemodynamic response to caffeine may be related to sex steroid hormone concentrations (22-24). When taken together, these studies suggest that men are more responsive to caffeine than women, a hypothesis supported by the findings in this study since caffeine had a greater potency in reducing stress MBF in men as compared with women (Fig. 5). Caffeine competitively blocks all adenosine receptors ( $A_{1}$, 
$\left.A_{2 A}, A_{2 B}, A_{3}\right)$, resulting in a compensatory increase in adenosine concentration, which in turn stimulates circulating chemoreceptors and other receptors (25). In adult mammals, it has been suggested that $A_{2 A}$ receptors are implicated in $\mathrm{O}_{2}$ sensing by carotid glomus cells (chemoreceptors) and are involved in the transduction mechanisms of $\mathrm{O}_{2}$ sensing in carotid bodies. Therefore, excessive adenosine can activate chemoreceptors via binding to $A_{2 A}$ receptors located in carotid bodies, thereby increasing sympathetic outflow of catecholamines leading to an increase in vascular resistance, and renin secretion (26). In this study, CVR was found to increase in men when the plasma caffeine concentration increased, while women had no significant changes in the CVR following ingestion of caffeine (Table 6). Gender-differences in the clearance of plasma-protein-binding and differences in the volume of distribution may also explain some of the differences in the perfusion response to caffeine between genders (27). Regional conditions favor regadenoson and dipyridamole over adenosine as the drugs of choice. Although only adenosine was evaluated in this study, it is likely that our findings can also apply to regadenoson and dipyridamole.

\section{Study Limitations}

This study was conducted in healthy young volunteers with normal cardiac perfusion without perfusion defects, and we cannot rule out that results would have differed in the typical patient population undergoing cardiac ${ }^{82} \mathrm{Rb}-\mathrm{PET}$ testing. Patients populations are often elderly and have an intermediate likelihood of ischemic heart disease in addition to lower sex hormone concentrations, caffeine pharmacokinetics, and pharmacodynamics. Combined, these differences might cause different hemodynamic responses than those reported in this study. However, we find that an establishment of 
gender-specific data in young normal volunteers is important prior to investigating the impact of caffeine consumption in an elderly cohort where comorbidities and coronary artery disease are common. Another limitation is that our study was conducted in a single center using only one imaging system, which might affect the overall MBF and MFR assessments.

\section{CONCLUSION}

In healthy volunteers, we found that caffeine consumption prior to myocardial perfusion imaging affected men and women differently. Associations between plasma caffeine and significant reductions in stress MBF and MFR were found at lower plasma caffeine concentrations in men when compared with women.

Disclosure. The authors have no conflict of interest. 


\section{KEY POINTS:}

Question: Does caffeine prior to stress MPI affect the hemodynamic response differently in women and men?

Pertinent findings: Caffeine consumption affects the hemodynamic response at a lower plasma caffeine concentration in men than women, with the stress myocardial blood flow (MBF) being affected with plasma concentrations of $1.2 \mathrm{mg} / \mathrm{l}$ in men as compared to $7.4 \mathrm{mg} / \mathrm{l}$ in women. Dose-response of caffeine plasma concentration and obtained stress MBF assessments revealed significantly increased sensitivity to caffeine in men when compared with women.

Implications for patient care: Caffeine consumption less than 12 hours MPI imaging sessions might lower the stress MBF assessments. At comparable plasma caffeine concentrations, men seem to be particularly affected and should be encouraged to abstain from caffeine for longer time periods than women prior to the myocardial perfusion imaging. 


\section{REFERENCES}

1. Klotz KN. Adenosine receptors and their ligands. Naunyn Schmiedebergs Arch Pharmacol. 2000;362:382-391.

2. Belardinelli L, Shryock JC, Snowdy S, et al. The A(2A) adenosine receptor mediates coronary vasodilation. J Pharmacol Exp Ther. 1998;284:1066-1073.

3. Sciagrà $R$, Lubberink $M$, Hyafil $F$, et al. EANM procedural guidelines for PET/CT quantitative myocardial perfusion imaging. Eur J Nucl Med Mol Imaging. 2020:Online ahead of print.

4. Kitkungvan D, Bui L, Johnson NP, et al. Quantitative myocardial perfusion positron emission tomography and caffeine revisited with new insights on major adverse cardiovascular events and coronary flow capacity. Eur Heart $J$ Cardiovasc Imaging. 2019;20:751-762.

5. Byrne C, Kjaer A, Wissenberg M, et al. Dose-dependent effect of caffeine on adenosine-induced myocardial stress perfusion in Rubidium-82 positron-emission tomography/computed tomography. JACC Cardiovasc Imaging. 2019;12:11021103.

6. Sdringola S, Johnson NP, Kirkeeide RL, Cid E, Gould KL. Impact of unexpected factors on quantitative myocardial perfusion and coronary flow reserve in young, asymptomatic volunteers. JACC Cardiovasc Imaging. 2011;4:402-412.

7. Mc Ardle BA, Dowsley TF, Dekemp RA, Wells GA, Beanlands RS. Does Rubidium-82 PET have superior accuracy to SPECT perfusion imaging for the diagnosis of obstructive coronary disease?: A systematic review and metaanalysis. J Am Coll Cardiol. 2012;60:1828-1837. 
8. Martyn D, Lau A, Richardson P, Roberts A. Temporal patterns of caffeine intake in the United States. Food Chem Toxicol. 2018;111:71-83.

9. Murthy VL, Bateman TM, Beanlands RS, et al. Clinical quantification of myocardial blood flow using PET: joint position paper of the SNMMI cardiovascular council and the ASNC. J Nucl Med. 2018;59:273-293.

10. Byrne C, Kjaer A, Olsen NE, Forman JL, Hasbak P. Test--retest repeatability and software reproducibility of myocardial flow measurements using rest/adenosine stress Rubidium-82 PET/CT with and without motion correction in healthy young volunteers. J Nucl Cardiol. 2020:1-12 (Online ahead of print).

11. Lortie M, Beanlands RSB, Yoshinaga K, Klein R, DaSilva JN, DeKemp RA. Quantification of myocardial blood flow with 82Rb dynamic PET imaging. Eur J Nucl Med Mol Imaging. 2007;34:1765-1774.

12. Ziadi MC, Dekemp RA, Williams KA, et al. Impaired myocardial flow reserve on rubidium-82 positron emission tomography imaging predicts adverse outcomes in patients assessed for myocardial ischemia. J Am Coll Cardiol. 2011;58:740-748.

13. Nakazato R, Berman DS, Dey D, et al. Automated quantitative Rb-82 3D PET/CT myocardial perfusion imaging: Normal limits and correlation with invasive coronary angiography. J Nucl Cardiol. 2012;19:265-276.

14. Freitag MT, Bremerich J, Wild D, Haaf P, Zellweger MJ, Caobelli F. Quantitative myocardial perfusion 82Rb-PET assessed by hybrid PET/coronary-CT: Normal values and diagnostic performance. J Nucl Cardiol. 2020:Online ahead of print.

15. Otaki $\mathrm{Y}$, Lassen ML, Manabe O, et al. Short-term repeatability of myocardial blood flow using $82 \mathrm{Rb}$ PET/CT: The effect of arterial input function position and motion 
correction. J Nucl Cardiol. 2019:1-8 (Ahead of print).

16. Kubo S, Tadamura E, Toyoda $\mathrm{H}$, et al. Effect of caffeine intake on myocardial hyperemic flow induced by adenosine triphosphate and dipyridamole. J Nucl Med. 2004;45:730-738.

17. Chareonthaitawee P, Kaufmann PA, Rimoldi O, Camici PG. Heterogeneity of resting and hyperemic myocardial blood flow in healthy humans. Cardiovasc Res. 2001;50:151-161.

18. Ribeiro-Alves MA, Trugo LC, Donangelo CM. Use of oral contraceptives blunts the calciuric effect of caffeine in young adult women. $J$ Nutr. 2003;133:393-398.

19. McIntosh VJ, Chandrasekera PC, Lasley RD. Gender differences in the cardiac A1 adenosine receptor anti-adrenergic effect. FASEB J. 2010;24:1041-1045.

20. Abdel-Rahman AR, Merrill RH, Wooles WR. Gender-related differences in the baroreceptor reflex control of heart rate in normotensive humans. J Appl Physiol. 1994;77:606-613.

21. Beske SD, Alvarez GE, Ballard TP, Davy KP. Gender difference in cardiovagal baroreflex gain in humans. J Appl Physiol. 2001;91:2088-2092.

22. Goldman RK, Azar AS, Mulvaney JM, Hinojosa-Laborde C, Haywood JR, Brooks VL. Baroreflex sensitivity varies during the rat estrous cycle: Role of gonadal steroids. Am J Physiol - Regul Integr Comp Physiol. 2009;296:1419-1426.

23. Minson CT, Kaplan P, Meendering JR, Torgrimson BN, Miller NP. Comments on women, hormones, and clinical trials: a beginning, not an end. J Appl Physiol. 2006;100:373.

24. Temple JL, Ziegler AM. Gender differences in subjective and physiological 
responses to caffeine and the role of steroid hormones. J Caffeine Res.

$2011 ; 1: 41-48$.

25. Echeverri D, Montes FR, Cabrera M, Galán A, Prieto A. Caffeine's vascular mechanisms of action. Int J Vasc Med. 2010;2010:eCollection 2019 (Online).

26. Koos BJ. Adenosine A2a receptors and $\mathrm{O} 2$ sensing in development. Am J Physiol Integr Comp Physiol. 2011;301:R601--R622.

27. Nehlig A. Interindividual differences in caffeine metabolism and factors driving caffeine consumption. Pharmacol Rev. 2018;70:384-411. 


\section{Tables}

Table 1. Heart rate (beats per minute) obtained during scans using four levels of plasma caffeine concentration. Significant variations in the heart rate between the baseline scans (plasma caffeine concentration $<1 \mathrm{mg} / \mathrm{l}$ ) and studies with increased plasma caffeine concentrations are marked by *. Intergender differences in the HR observed for the respective plasma caffeine concentrations are marked by ${ }^{\dagger}$. Numbers given in parenthesis for the rest scans indicate the number of MPI sessions fulfilling the criteria. Differences were considered significant for $p<0.05$.

\begin{tabular}{|c|c|c|c|c|}
\hline $\begin{array}{l}\text { Plasma } \\
\text { caffeine } \\
\text { concentration } \\
(\mathrm{mg} / \mathrm{l})\end{array}$ & $\leq 1$ & $1<x \leq 3$ & $3<x \leq 5$ & $>5$ \\
\hline \multicolumn{5}{|c|}{ Rest } \\
\hline Women & $\begin{array}{l}62.4 \pm 10.8 \\
(31)\end{array}$ & $\begin{array}{l}51.4 \pm 7.3^{*} \\
\text { (8) }\end{array}$ & $\begin{array}{l}68.0 \pm 14.3 \\
(6)\end{array}$ & $\begin{array}{l}60.9 \pm 10.6 \\
(29)\end{array}$ \\
\hline Men & $\begin{array}{l}60.2 \pm 13.0 \\
(38)\end{array}$ & $\begin{array}{l}53.8 \pm 12.1 \\
(12)\end{array}$ & $\begin{array}{l}55.7 \pm 9.0^{\dagger} \\
(14)\end{array}$ & $\begin{array}{l}60.1 \pm 9.3 \\
(14)\end{array}$ \\
\hline \multicolumn{5}{|c|}{ Stress } \\
\hline Women & $92.5 \pm 14.4$ & $79.3 \pm 23.6^{*}$ & $91.5 \pm 9.7$ & $78.2 \pm 15.2^{\star}$ \\
\hline Men & $80.9 \pm 19.7^{\dagger}$ & $73.3 \pm 18.8$ & $74.4 \pm 15.8^{\dagger}$ & $70.6 \pm 13.2$ \\
\hline
\end{tabular}


Table 2. Test-retest repeatability (measured as the coefficient of variation) for the baseline MPI sessions ( $0 \mathrm{mg}$ caffeine ingested). No differences were in the test-retest repeatability was observed between the two genders.

\begin{tabular}{|l|c|c|c|}
\hline & Rest & Stress & MFR \\
\hline Women & $13.5 \%$ & $10.6 \%$ & $12.9 \%$ \\
\hline Men & & & \\
$(\mathrm{N}=20)$ & $16.1 \%$ & $18.4 \%$ & $20.6 \%$ \\
\hline $\begin{array}{l}\text { Combined } \\
(\mathrm{N}=39)\end{array}$ & $15.8 \%$ & $15.3 \%$ & $17.8 \%$ \\
\hline
\end{tabular}


Table 3. Diastolic blood pressure obtained during scans using four levels of plasma caffeine concentration. Significant variations in the diastolic blood pressure between the baseline scans (plasma caffeine concentration $<1 \mathrm{mg} / \mathrm{l}$ ) and studies with increased plasma caffeine concentrations are marked by *. Intergender differences in the diastolic blood pressure observed for the respective plasma caffeine concentrations are marked by ${ }^{\dagger}$. Numbers given in parenthesis for the rest scans indicate the number of MPI sessions fulfilling the criteria. Differences were considered significant for $p<0.05$.

\begin{tabular}{|c|c|c|c|c|}
\hline $\begin{array}{l}\text { Plasma } \\
\text { caffeine } \\
\text { concentration } \\
(\mathrm{mg} / \mathrm{l})\end{array}$ & $\leq 1$ & $1<x \leq 3$ & $3<x \leq 5$ & $>5$ \\
\hline \multicolumn{5}{|c|}{ Rest } \\
\hline Women & $\begin{array}{l}60.9 \pm 6.5 \\
(31)\end{array}$ & $\begin{array}{l}62.3 \pm 4.6 \\
\text { (8) }\end{array}$ & $\begin{array}{l}60.5 \pm 8.3 \\
\text { (6) }\end{array}$ & $\begin{array}{l}64.2 \pm 6.4 \\
(29)\end{array}$ \\
\hline Men & $\begin{array}{l}57.9 \pm 9.1 \\
(38)\end{array}$ & $\begin{array}{l}61.2 \pm 7.3 \\
(12)\end{array}$ & $\begin{array}{l}60.4 \pm 5.7 \\
(14)\end{array}$ & $\begin{array}{l}62.2 \pm 5.7 \\
(14)\end{array}$ \\
\hline \multicolumn{5}{|c|}{ Stress } \\
\hline Women & $60.8 \pm 9.0$ & $68.4 \pm 10.2$ & $60.4 \pm 5.7$ & $66.3 \pm 8.8^{*}$ \\
\hline Men & $54.7 \pm 9.0^{\dagger}$ & $61.0 \pm 9.8^{*}$ & $58.7 \pm 8.1$ & $59.5 \pm 6.8^{\dagger}$ \\
\hline
\end{tabular}


Table 4. Systolic blood pressure obtained during scans using four plasma caffeine concentration. Within-gender variations in the systolic blood pressure between the baseline scans (plasma caffeine concentration $<1 \mathrm{mg} / \mathrm{l}$ ) and studies with increased plasma caffeine concentrations are marked by *. Intergender differences in the systolic blood pressure observed for the respective plasma caffeine concentrations are marked by ${ }^{\dagger}$. Numbers given in parenthesis for the rest scans indicate the number of MPI sessions fulfilling the criteria. Differences were considered significant for $p<0.05$.

\begin{tabular}{|c|c|c|c|c|}
\hline $\begin{array}{l}\text { Plasma } \\
\text { caffeine } \\
\text { concentration } \\
(\mathrm{mg} / \mathrm{l})\end{array}$ & $\leq 1$ & $1<x \leq 3$ & $3<x \leq 5$ & $>5$ \\
\hline \multicolumn{5}{|c|}{ Rest } \\
\hline Women & $\begin{array}{l}102.6 \pm 9.9 \\
(31)\end{array}$ & $\begin{array}{l}103.9 \pm 8.1 \\
\text { (8) }\end{array}$ & $\begin{array}{l}99.2 \pm 17.3 \\
(6)\end{array}$ & $\begin{array}{l}108.7 \pm 13.6 \\
(29)\end{array}$ \\
\hline Men & $\begin{array}{l}108.9 \pm 10.7 \\
(38)\end{array}$ & $\begin{array}{l}112.6 \pm 10.0 \\
(12)\end{array}$ & $\begin{array}{l}112.5 \pm 10.7 \\
(14)\end{array}$ & $\begin{array}{l}114.9 \pm 9.3 \\
(14)\end{array}$ \\
\hline \multicolumn{5}{|c|}{ Stress } \\
\hline Women & $92.5 \pm 14.4$ & $96.5 \pm 17.7$ & $102.3 \pm 6.4$ & $105.9 \pm 12.3$ \\
\hline Men & $107.0 \pm 12.7^{\dagger}$ & $110.6 \pm 13.5$ & $112.1 \pm 10.1^{\dagger}$ & $111.5 \pm 12.1$ \\
\hline
\end{tabular}


Table 5. RPP stratified for the two observed for the two genders at four levels of plasma caffeine concentration. ${ }^{*}$ indicates gender-specific differences between the baseline scan $(0 \mathrm{mg})$ and the respective plasma caffeine concentrations. Numbers given in parenthesis for the rest scans indicate the number of MPI sessions fulfilling the criteria. Differences were considered significant for $p<0.05$.

\begin{tabular}{|c|c|c|c|c|}
\hline $\begin{array}{l}\text { Plasma } \\
\text { caffeine } \\
\text { concentration } \\
(\mathrm{mg} / \mathrm{l})\end{array}$ & $\leq 1$ & $1<x \leq 3$ & $3<x \leq 5$ & $>5$ \\
\hline \multicolumn{5}{|c|}{ Rest } \\
\hline Women & $\begin{array}{l}6422 \pm 1381 \\
(31)\end{array}$ & $\begin{array}{l}5329 \pm 797^{*} \\
\text { (8) }\end{array}$ & $\begin{array}{l}6626 \pm 1253 \\
(6)\end{array}$ & $\begin{array}{l}6627 \pm 1475 \\
(29)\end{array}$ \\
\hline Men & $\begin{array}{l}6504 \pm 1381 \\
(38)\end{array}$ & $\begin{array}{l}6100 \pm 1739 \\
(12)\end{array}$ & $\begin{array}{l}6429 \pm 1075 \\
(14)\end{array}$ & $\begin{array}{l}6786 \pm 1447 \\
(14)\end{array}$ \\
\hline \multicolumn{5}{|c|}{ Stress } \\
\hline Women & $9624 \pm 2013$ & $7480 \pm 2093^{*}$ & $9328 \pm 702$ & $8333 \pm 2105^{*}$ \\
\hline Men & $8742 \pm 2350$ & $8208 \pm 2757$ & $8279 \pm 1666$ & $7770 \pm 1703$ \\
\hline
\end{tabular}


Table 6. Coronary vascular resistance (CVR) obtained for rest and stress using four levels of plasma caffeine concentration. Significant differences for men and women are shown by ${ }^{\dagger}$, while ${ }^{*}$ indicates gender-specific differences between the baseline scan $(0 \mathrm{mg})$ and the respective plasma caffeine concentrations. Numbers given in parenthesis for the rest scans indicate the number of MPI sessions fulfilling the criteria. Differences were considered significant for $p<0.05$.

\begin{tabular}{|c|c|c|c|c|}
\hline $\begin{array}{l}\text { Plasma } \\
\text { caffeine } \\
\text { concentration } \\
(\mathrm{mg} / \mathrm{l})\end{array}$ & $\leq 1$ & $1<x \leq 3$ & $3<x \leq 5$ & $>5$ \\
\hline \multicolumn{5}{|c|}{ Rest } \\
\hline Women & $\begin{array}{l}82.9 \pm 19.4 \\
(31)\end{array}$ & $\begin{array}{l}85.7 \pm 16.8 \\
(8)\end{array}$ & $\begin{array}{l}77.0 \pm 18.5 \\
(6)\end{array}$ & $\begin{array}{l}92.6 \pm 21.1 \\
(29)\end{array}$ \\
\hline Men & $\begin{array}{l}105.5 \pm 30.7^{\dagger} \\
(38)\end{array}$ & $\begin{array}{l}101.3 \pm 26.5 \\
(12)\end{array}$ & $\begin{array}{l}102.1 \pm 27.6 \\
(14)\end{array}$ & $\begin{array}{l}152.9 \pm 25.9^{* \dagger} \\
(14)\end{array}$ \\
\hline \multicolumn{5}{|c|}{ Stress } \\
\hline Women & $25.8 \pm 5.9$ & $23.0 \pm 7.2$ & $21.8 \pm 1.4$ & $23.6 \pm 8.8$ \\
\hline Men & $27.5 \pm 8.2$ & $33.0 \pm 15.2$ & $45.2 \pm 25.6^{\star \dagger}$ & $51.8 \pm 14.8^{\star \star \dagger}$ \\
\hline
\end{tabular}




\section{Figures}

Fig. 1 Imaging protocol. (A) Acquisition protocol for each of the 4 PET/CT imaging sessions. Both rest and stress scans were acquired over 6 minutes. (B) Study protocol for the 40 healthy volunteers.

A

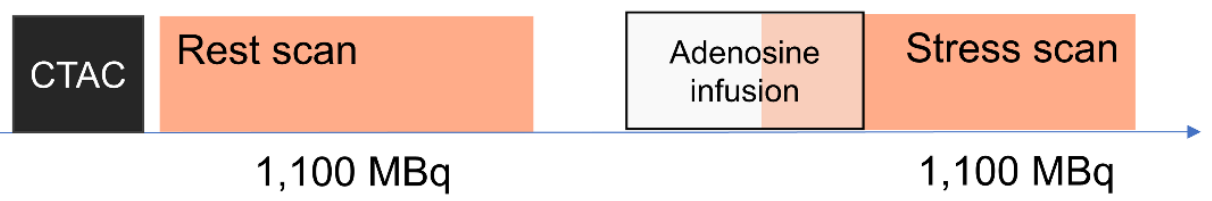

B

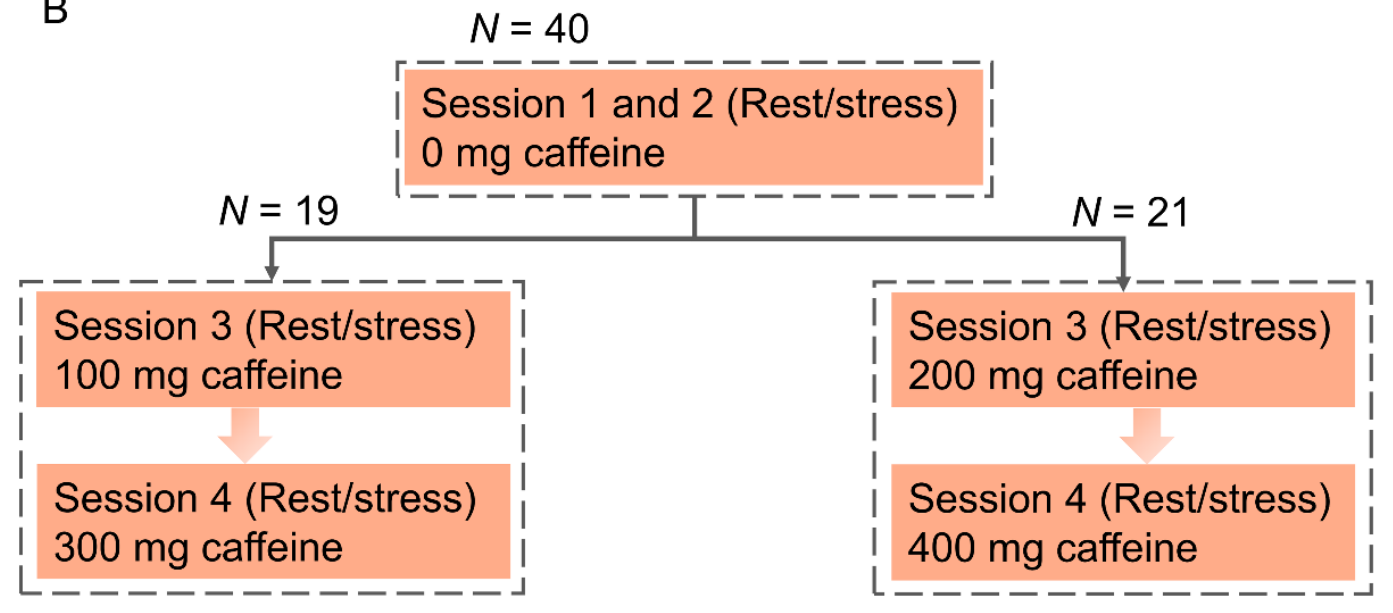

CTAC (computed tomographic attenuation correction) 
Fig. 2. rest MBF (myocardial blood flow) obtained in the volunteers sorted by gender and plasma caffeine concentration with and without RPP correction.
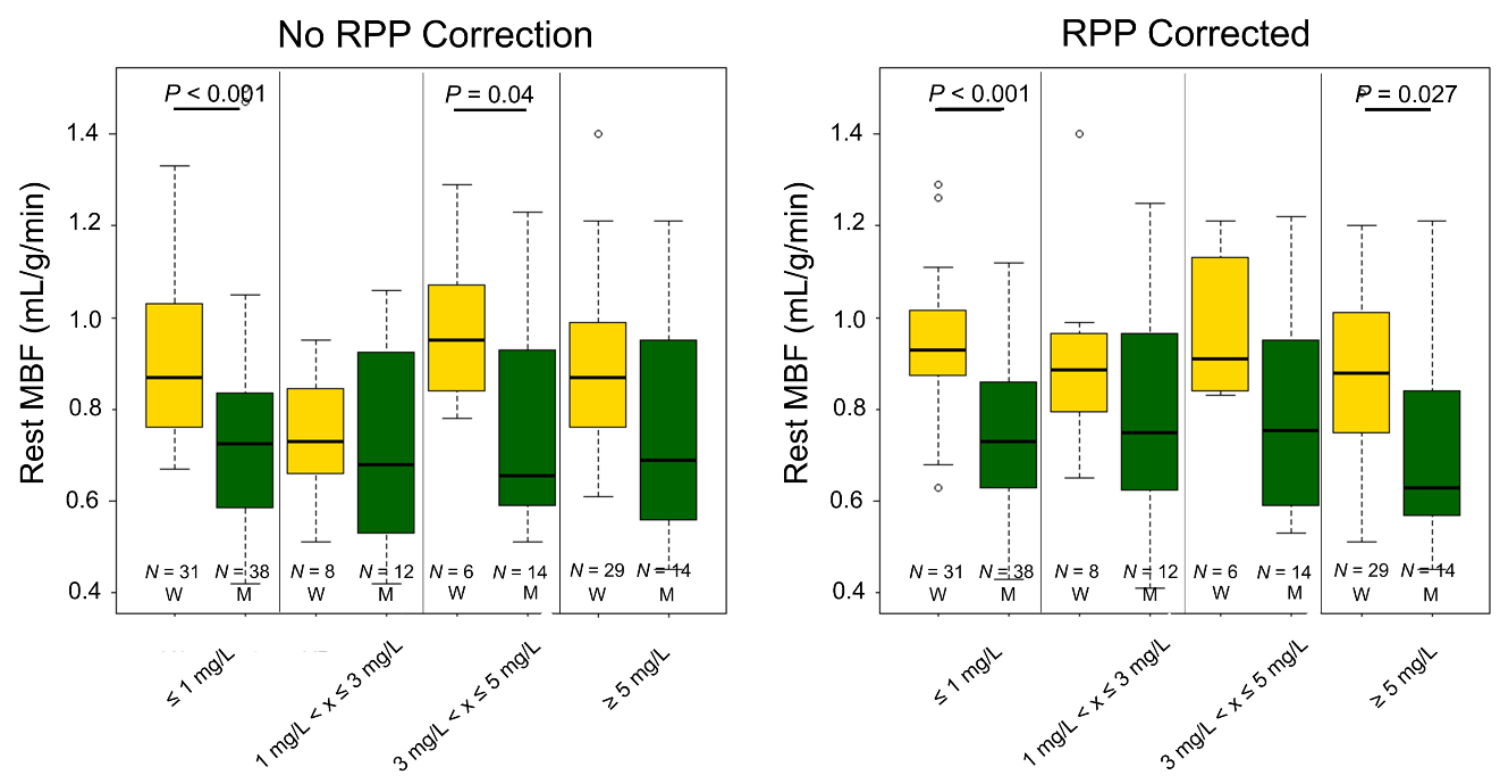

$\mathrm{W}=$ Women, $\mathrm{M}=$ Men, $\mathrm{RPP}=$ rate pressure product, $\mathrm{N}=$ Number of MPI sessions fulfilling the criteria 
Fig. 3. Stress MBF (myocardial blood flow) obtained in the volunteers sorted by gender and plasma caffeine concentration, with and without RPP correction.
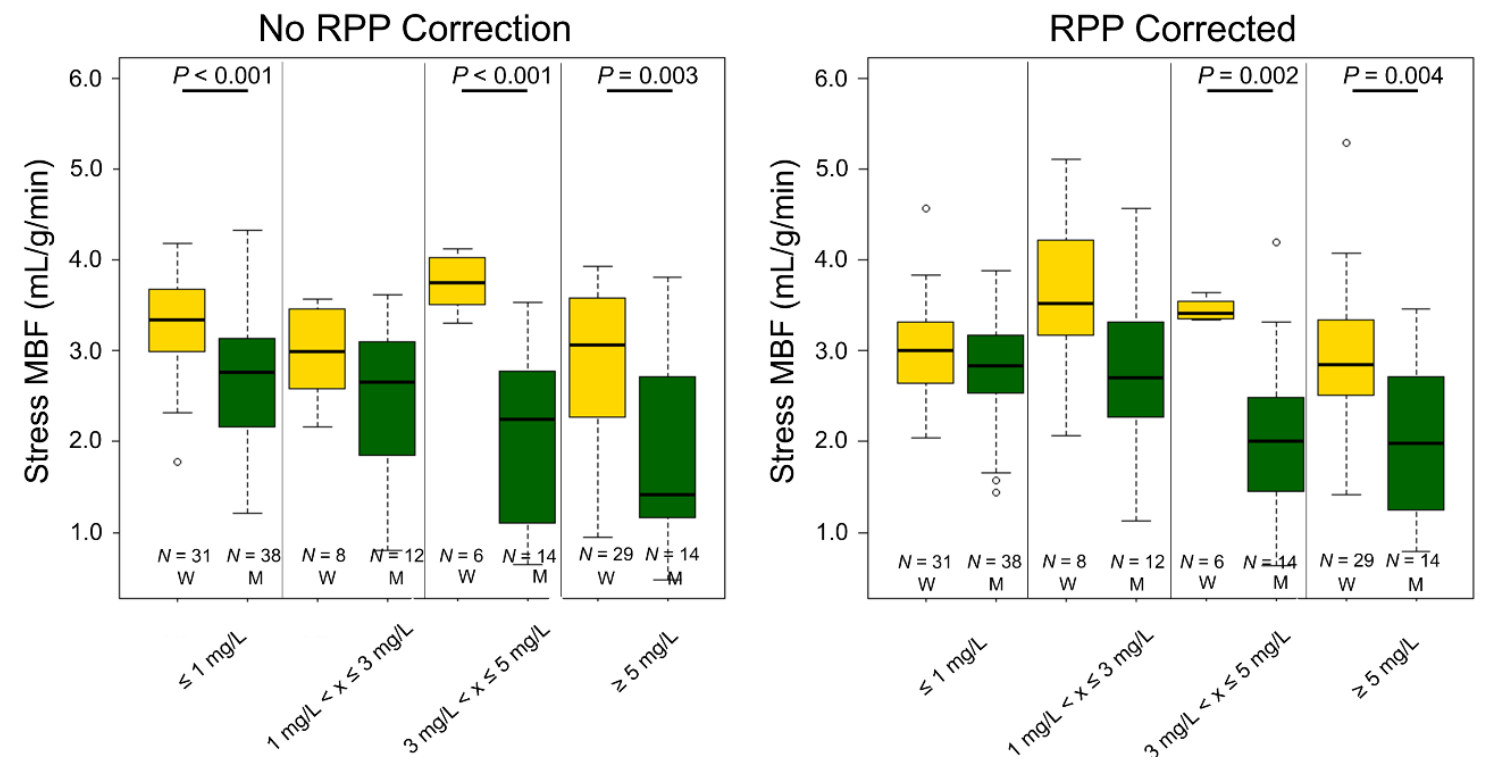

$\mathrm{W}=$ Women, $\mathrm{M}=$ Men, $\mathrm{RPP}=$ rate pressure product, $\mathrm{N}=$ Number of $\mathrm{MPI}$ sessions fulfilling the criteria 
Fig. 4. Relationship between ingested caffeine $(\mathrm{mg})$ and the corresponding plasma caffeine concentrations (mg/l). The plasma caffeine concentrations obtained at 75 and 90 minutes are given as mean \pm SEM in both men (closed blue triangles, $n=9-20$ ) and women (closed red circles, $n=9-18)$.

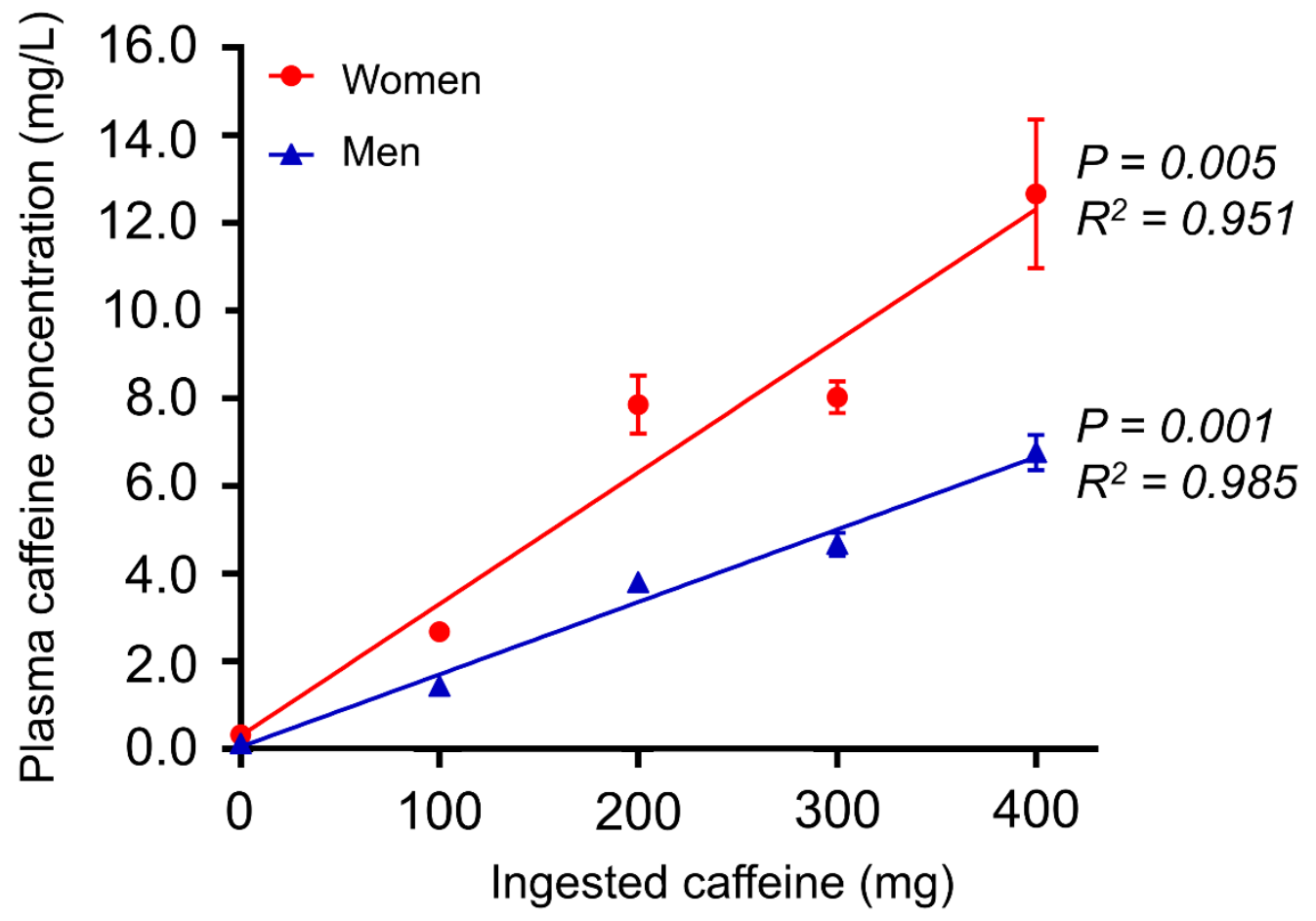

SEM $=$ standard error of the mean 
Fig. 5. Relationship between average plasma concentration of caffeine [mg/l] $(\mathrm{log})$ and stress MBF. Points represent mean values, and vertical lines indicate SEM. MBF values were normalized to the maximum stress MBF obtained for the individual volunteers ((men, closed blue triangles, $\mathrm{n}=9-20)$ and women (closed red circles, $\mathrm{n}=9-18)$, respectively).

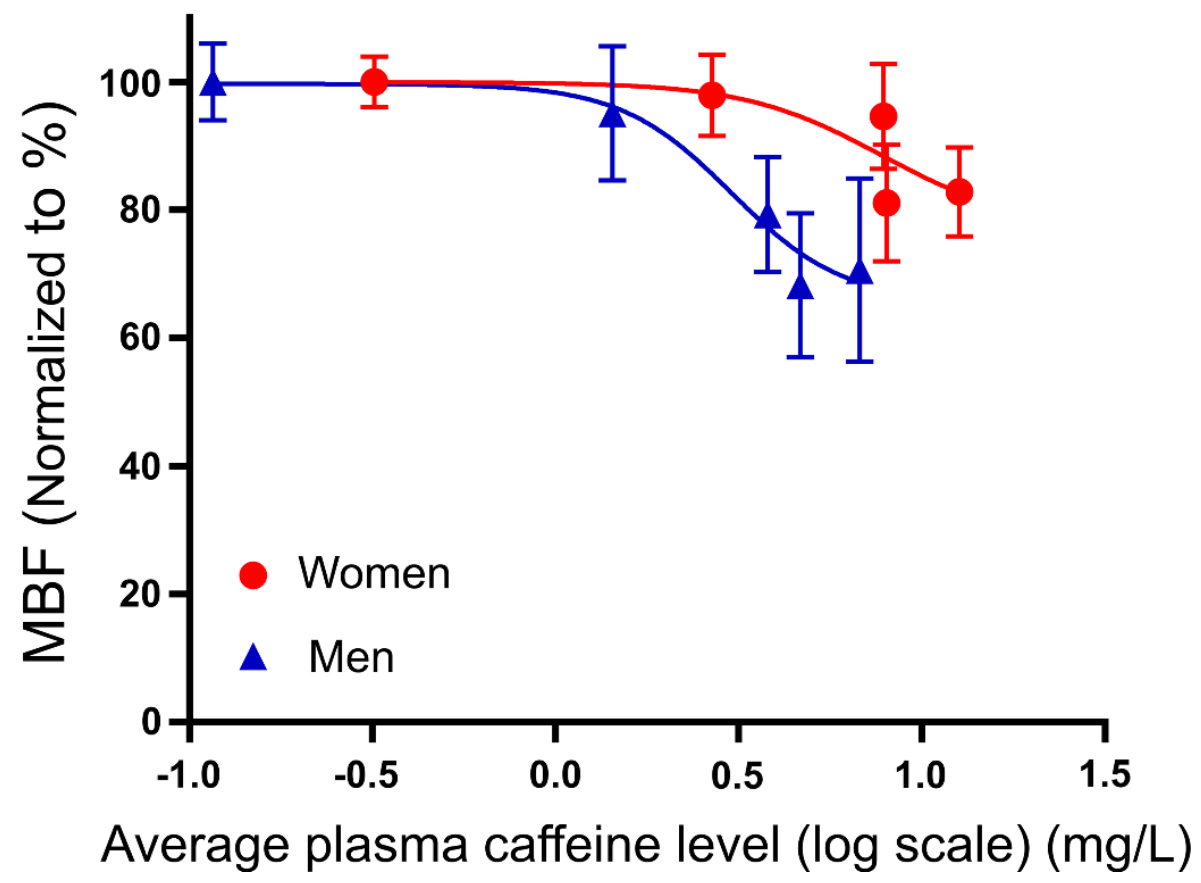

$\mathrm{SEM}=$ standard error of the mean, $\mathrm{MBF}=$ myocardial blood flow 
Fig. 6. MFR obtained in the volunteers sorted by gender and plasma caffeine levels
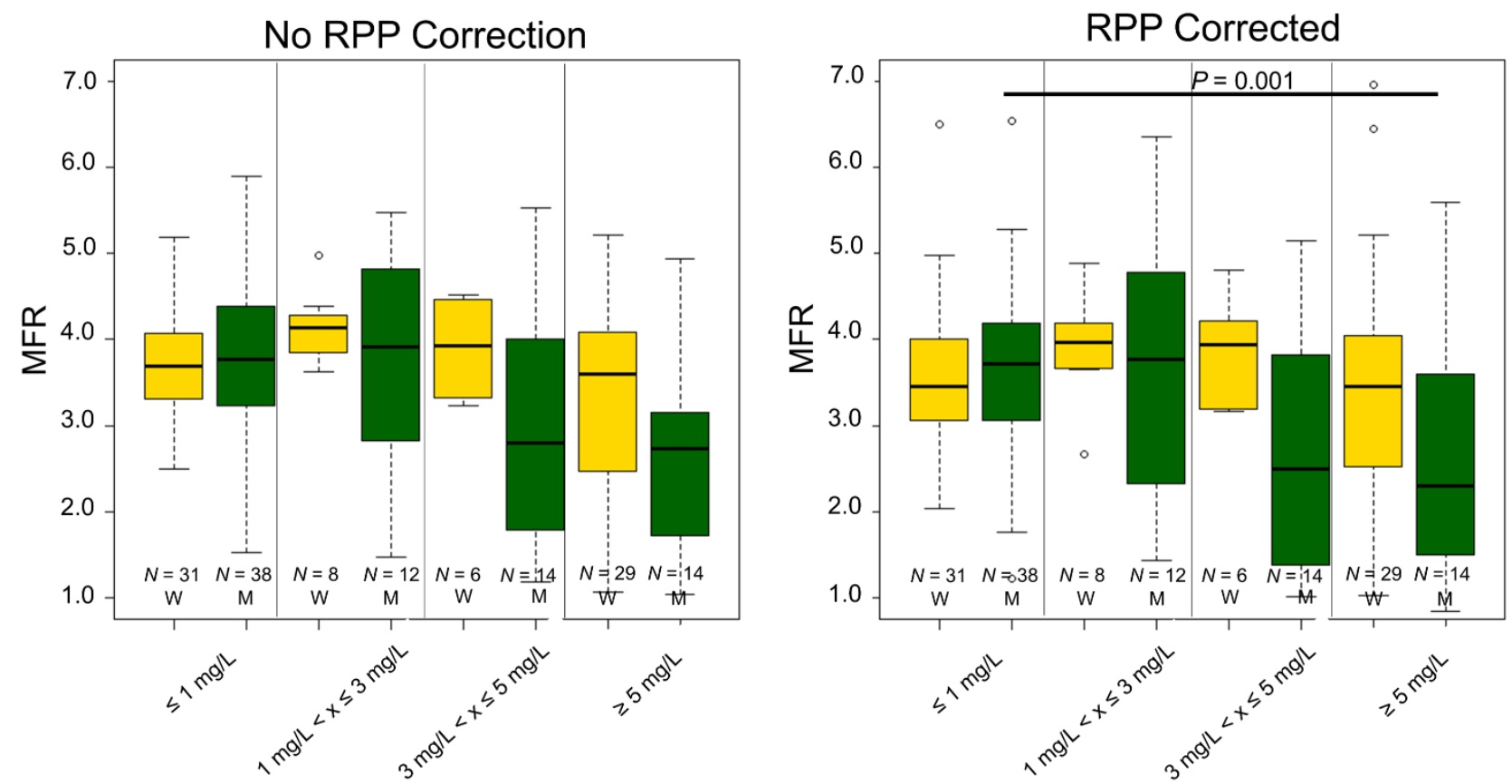

$\mathrm{W}=$ Women, $\mathrm{M}=$ men, $\mathrm{MFR}=$ myocardial flow reserve, $\mathrm{RPP}=$ rate pressure product, $\mathrm{N}$

$=$ Number of MPI sessions fulfilling the criteria 


\section{Graphical Abstract}
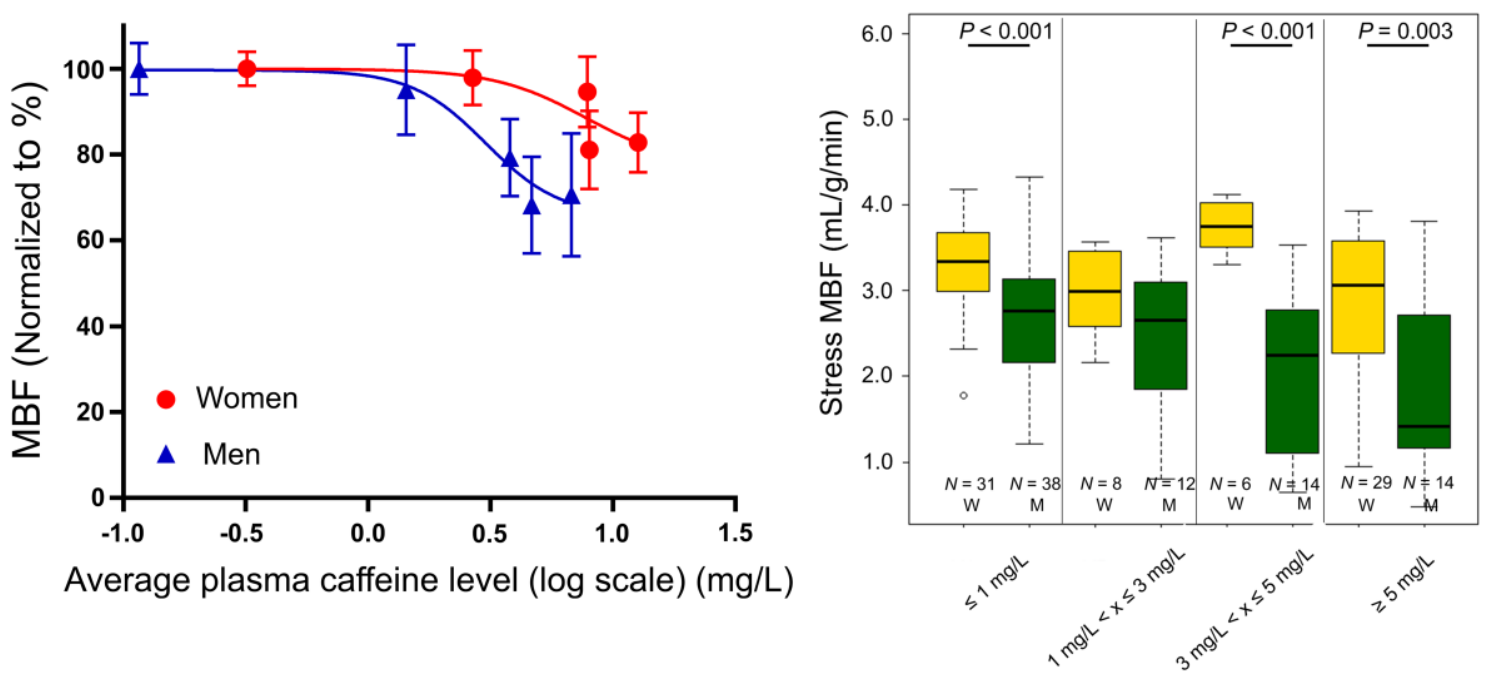